\title{
Limitations to Photosynthesis in Leaves of Wheat Plants Infected by Pyricularia oryzae
}

\author{
Daniel Debona, Fabrício Ávila Rodrigues, Jonas Alberto Rios, \\ Samuel Cordeiro Vitor Martins, Lucas Felisberto Pereira, and Fábio Murilo DaMatta
}

First, second, and third authors: Viçosa Federal University, Department of Plant Pathology, Laboratory of Host-Parasite Interaction, and fourth, fifth, and sixth authors: Viçosa Federal University, Department of Biology, Viçosa, Minas Gerais State, 36570-000, Brazil. Accepted for publication 19 July 2013

\begin{abstract}
Debona, D., Rodrigues, F. A., Rios, J. A., Martins, S. C. V., Pereira, L. F., and DaMatta, F. M. 2014. Limitations to photosynthesis in leaves of wheat plants infected by Pyricularia oryzae. Phytopathology 104:34-39.

Blast, caused by Pyricularia oryzae, has become an economically important disease in wheat in Brazil, but little effort has been devoted to understanding the wheat $-P$. oryzae interaction. This study was intended to determine the effects of $P$. oryzae infection on the photosynthetic process in wheat plants using a susceptible (BR 18) and a partially resistant cultivar (BRS 229). It was found that the net carbon assimilation rate $(A)$, stomatal conductance $\left(g_{s}\right)$, and transpiration rate were dramatically reduced in both cultivars due to $P$. oryzae infection but to a lesser degree in BRS 229. Photosynthesis was impaired in asymptomatic leaf tissues, indicating that blast severity is not an acceptable indicator for predicting $P$. oryzae-induced reductions in $A$. The proportionally larger decreases in $A$ than in $g_{s}$, in parallel with increases in internal $\mathrm{CO}_{2}$ concentration $\left(C_{\mathrm{i}}\right)$,
\end{abstract}

ABSTRACT suggest that the lower influx of $\mathrm{CO}_{2}$ into the diseased leaves caused by stomatal closure was not a prominent factor associated with the reduction in $A$. Additional support for this conclusion comes from the nonsignificant correlation between $A$ and $g_{s}$, the negative correlation between $A$ and $C_{\mathrm{i}}$ and the positive correlation between blast severity and $C_{\mathrm{i}}$. Both the maximum rate of carboxylation and the maximum rate of electron transport were dramatically depressed at advanced stages of $P$. oryzae infection, mainly in BR 18, although the reduction in $A$ was not closely related to the decrease in the electron transport rate. In conclusion, biochemical limitations likely related to the reduced activity of Rubisco, rather than diffusive limitations, were the main factor associated with decreases in $A$ during the infection process of $P$. oryzae on wheat leaves.

Additional keywords: carboxylation capacity, gas exchange variables, stomatal limitations, Triticum aestivum, wheat blast.

(5). Both diffusive and biochemical factors have been invoked as prime causes associated with impaired photosynthesis in diseased leaves $(6,12)$. Fungal infection can also affect the net carbon assimilation rate $(A)$ by increasing leaf respiration, which is necessary for supplying the demand caused by the accelerated metabolic activity of the host cells (29). In any case, despite many efforts to elucidate the mechanisms by which pathogens are capable of affecting photosynthetic capacity, actual knowledge of the subject remains far from comprehensive.

To conceptually integrate the various responses of the photosynthetic process to leaf diseases, modeling is required. At the leaf level, the widely accepted model of Farquhar et al. (16), based on the response of $A$ to varying internal $\mathrm{CO}_{2}$ concentrations $\left(A / C_{\mathrm{i}}\right.$ curve $)$, has routinely been adopted for describing the photosynthetic process. This model uses two parameters that largely determine the biochemical capacities of the photosynthetic apparatus: the apparent in vivo activity of ribulose-1,5-bisphosphate carboxylase/oxygenase (Rubisco), also termed the maximum rate of carboxylation $\left(V_{\mathrm{cmax}}\right)$ and the maximum rate of electron transport used during ribulose-1,5-bisphosphate (RuBP) regeneration $\left(J_{\max }\right)(28)$. Results from modeling $A / C_{\mathrm{i}}$ curves suggest that pathogen-related decreases in $A$ are governed chiefly by biochemical impairments at the chloroplast level, as demonstrated by the reductions in $V_{\text {cmax }}$ in sweet orange infected by Xylella fastidiosa (23) and in bean leaves infected by Uromyces appendiculatus (4). Decreases in both $V_{\text {cmax }}$ and $J_{\max }$ have also been reported for tomato plants infected by Fusarium oxysporum f. sp. lycopersici (32) and in eucalyptus infected by Mycosphaerella spp. (34).

Although blast has become one of the most important diseases of wheat, studies of wheat $-P$. oryzae interaction remain limited.

http://dx.doi.org/10.1094/PHYTO-01-13-0024-R

(C) 2014 The American Phytopathological Society 
Considering the lack of information regarding physiological changes in the leaves of wheat plants during the infectious process of $P$. oryzae, the present study aimed at investigating the changes in leaf gas exchange variables and the mechanisms involved in these changes. It is hypothesized (i) that decreases in photosynthetic rates due to $P$. oryzae infection result from changes in the rates of the biochemical reactions of photosynthesis and (ii) that this decrease is proportional to the reduction in green leaf tissues. To test these hypotheses, blast severity, instantaneous gas exchange traits, and parameters derived from $A / C_{\mathrm{i}}$ curves were assessed in two wheat cultivars with different levels of resistance to blast.

\section{MATERIALS AND METHODS}

Plant growth. Wheat seeds from cultivars BR 18 and BRS 229 were surface-sterilized in $10 \%\left(\mathrm{vol} \mathrm{vol}^{-1}\right) \mathrm{NaOCl}$ for $2 \mathrm{~min}$, rinsed in sterilized water for $3 \mathrm{~min}$, and sown in plastic pots $(20-\mathrm{cm}$ diameter) filled with $1 \mathrm{~kg}$ of substrate made from a 1:1:1 mixture of pine bark, peat, and expanded vermiculite (Tropstrato, Vida Verde, Mogi Mirim, SP, Brazil). Previous studies showed that cultivars BR 18 and BRS 229 were, respectively, susceptible and partially resistant to leaf blast at the vegetative growth stage $(11,13)$. A total of $1.63 \mathrm{~g}$ of calcium phosphate monobasic was added to each plastic pot. A total of 12 seeds were sown per pot, and 5 days after seedling emergence, each pot was thinned to six seedlings. Substrate in each pot was fertilized with a nutrient solution containing, in $\mathrm{g} \mathrm{liter}^{-1}, 6.4 \mathrm{KCl}, 3.48 \mathrm{~K}_{2} \mathrm{SO}_{4}, 5.01 \mathrm{MgSO}_{4}$. $7 \mathrm{H}_{2} \mathrm{O}, 2.03\left(\mathrm{NH}_{2}\right)_{2} \mathrm{CO}, 0.009 \mathrm{NH}_{4} \mathrm{MO}_{7} \mathrm{O}_{24} \cdot 4 \mathrm{H}_{2} \mathrm{O}, 0.054 \mathrm{H}_{3} \mathrm{BO}_{3}$, $0.222 \mathrm{ZnSO}_{4} \cdot 7 \mathrm{H}_{2} \mathrm{O}, 0.058 \mathrm{CuSO}_{4} \cdot 5 \mathrm{H}_{2} \mathrm{O}$, and $0.137 \mathrm{MnCl}_{2}$. $4 \mathrm{H}_{2} \mathrm{O}$ (17). A volume of $15 \mathrm{ml}$ of nutrient solution containing $0.27 \mathrm{~g}$ of $\mathrm{FeSO}_{4} \cdot 7 \mathrm{H}_{2} \mathrm{O}$ and $0.37 \mathrm{~g}$ of EDTA bisodic liter ${ }^{-1}$ was also applied after seedling emergence. The nutrient solution was prepared using deionized water; $30 \mathrm{ml}$ per pot was applied after seedling emergence every week. Plants were watered as needed with deionized water.

Inoculum production and inoculation procedure. A pathogenic isolate of $P$. oryzae (UFV/DFP-01), obtained from ears of wheat plants (cultivar BR 18), was used to inoculate the leaves of wheat plants. The isolate was preserved on strips of filter paper placed into glass tubes containing silica gel at $4^{\circ} \mathrm{C}$. Pieces of filter paper with fungal mycelia were transferred to petri dishes containing potato dextrose agar (PDA). After 3 days, PDA plugs containing fungal mycelia were transferred to new petri dishes containing oat media. These petri dishes were kept in a growth chamber at $25^{\circ} \mathrm{C}$ with a 12 -h photoperiod during 10 days. After this period, mycelia producing conidia were carefully removed from the petri dishes with a rubber policeman to obtain a suspension of conidia. Plants were inoculated with a conidial suspension of $P$. oryzae $\left(10^{5}\right.$ conidia $\left.\mathrm{ml}^{-1}\right)$ at 30 days after emergence (growth stage 19) (42). Twenty-five milliliters of suspension was applied as a fine mist to the adaxial leaf blades of each plant until runoff with a VL Airbrush atomizer (Paasche Airbrush Co., Chicago, IL). Gelatin ( $1 \%$, wt vol ${ }^{-1}$ ) was added to the suspension to aid conidial adhesion to the leaf blades. Immediately after inoculation, the plants were transferred to a growth chamber with a temperature of $25 \pm 2{ }^{\circ} \mathrm{C}$ and a relative humidity of $90 \pm 5 \%$ and were subjected to an initial 24-h dark period. After this period, the plants were transferred to a plastic mist growth chamber (MGC) inside a greenhouse for the duration of the experiment. The MGC was made of wood ( $2 \mathrm{~m}$ wide, $1.5 \mathrm{~m}$ high, and $5 \mathrm{~m}$ long) and covered with $100-\mu \mathrm{m}$-thick transparent plastic. The temperature inside the MGC ranged from $25 \pm 2{ }^{\circ} \mathrm{C}$ (day) to $20 \pm 2{ }^{\circ} \mathrm{C}$ (night). The relative humidity was maintained at $92 \pm 3 \%$ using a misting system in which nozzles (model NEB-100; KGF Company, São Paulo, Brazil) sprayed mist every 30 min above the plant canopy. Relative humidity and temperature were measured with a thermohygrograph (TH-508, Impac, Brazil). The maximum natural photon flux density at plant canopy height was approximately $900 \mu \mathrm{mol} \mathrm{m} \mathrm{m}^{-2} \mathrm{~s}^{-1}$.

Assessment of blast severity. The fifth leaf from the base of each plant per replication of each treatment was marked and used to evaluate blast severity at 72 and $96 \mathrm{~h}$ after inoculation (hai) using a scale proposed by IRRI (26).

Gas exchange variables. Gas exchange variables were measured using the fifth leaf, from the base to the top, of noninoculated and inoculated plants from cultivars BR 18 and BRS 229 for each replication at 48,72 , and 96 hai. The net carbon assimilation rate $(A)$, stomatal conductance to water vapor $\left(g_{s}\right)$, internal $\mathrm{CO}_{2}$ concentration $\left(C_{\mathrm{i}}\right)$, and transpiration rate $(E)$ were estimated from 09:00 to 12:00 h (solar time) using a portable open-system infrared gas analyzer (LI-6400, LI-COR Inc., Lincoln, NE) under an external $\mathrm{CO}_{2}$ concentration of $400 \mu \mathrm{mol} \mathrm{mol}{ }^{-1}$ air. All of the measurements were conducted under artificial, saturating photon irradiance $\left(1,000 \mu \mathrm{mol} \mathrm{m} \mathrm{m}^{-2} \mathrm{~s}^{-1}\right)$ at the leaf level. To produce the $A / C_{\mathrm{i}}$ curves, measurements began at $400 \mu \mathrm{mol} \mathrm{CO} \mathrm{Col}^{-1}$ air, and once the steady-state was reached, the $\mathrm{CO}_{2}$ concentration was gradually lowered to $75 \mu \mathrm{mol} \mathrm{mol}{ }^{-1}$ and then increased stepwise to $1,750 \mu \mathrm{mol} \mathrm{mol}{ }^{-1}$. Nonlinear regression techniques, based on the equations of Farquhar et al. (16) and later modified by Sharkey (36) and Harley and Sharkey (24), were used to estimate the maximum rate of carboxylation $\left(V_{\mathrm{cmax}}\right)$, the maximum rate of electron transport used in RuBP regeneration $\left(J_{\max }\right)$, and the rate of respiration $\left(R_{\mathrm{d}}\right)$ for each $A / C_{\mathrm{i}}$ curve. The $J_{\max } / V_{\text {cmax }}$ ratio was also calculated. During the photosynthetic measurements, the relative humidity was $80 \pm 5 \%$ and the leaf temperature was $25 \pm$ $2^{\circ} \mathrm{C}$. The values of $V_{\mathrm{cmax}}, J_{\max }$, and $R_{\mathrm{d}}$ were corrected for $25^{\circ} \mathrm{C}$ (28).

Experimental design and data analysis. A $2 \times 2$ factorial experiment consisting of two wheat cultivars (BR 18 and BRS 229 ) and plants noninoculated or inoculated with $P$. oryzae was arranged in a completely randomized design with four replications. Each experimental unit consisted of one plastic pot with six plants. The measurements were made on the same leaf (one per pot) of the same mainshoot at each of the three measurement times (48, 72, and 96 hai). The experiment was repeated once. Data from all variables were analyzed by analysis of variance (ANOVA), and the means from the noninoculated and inoculated treatments for each cultivar and evaluation time were compared by $t$ test $(P \leq$ 0.05) using SAS (version 6.12; SAS Institute, Inc., Cary, NC). For severity, the ANOVA was considered to be a $2 \times 2$ factorial experiment consisting of two wheat cultivars and two evaluation times (72 and 96 hai). For the gas exchange variables, the ANOVA was considered to be a $2 \times 2 \times 3$ factorial experiment consisting of two wheat cultivars, noninoculated or inoculated plants, and three evaluation times. The Pearson linear correlation technique was used to determine the relationships among $A, g_{s}$, $C_{\mathrm{i}}, E$, and blast severity.

\section{RESULTS}

The factors, cultivars, and evaluation times, as well as their interactions, were significant for blast severity (Table 1). Blast severity was significantly lower in BRS 229 than in BR 18 (Fig. 1). From 72 to 96 hai, blast severity increased slightly in BRS 229 , from 18 to $22 \%$, and more markedly in BR 18 , from 31 to

TABLE 1. Analysis of variance of the effects of cultivars and evaluation times for blast severity

\begin{tabular}{lcc}
\hline Sources of variation & df & $F$ values $^{\mathrm{z}}$ \\
\hline Cultivars (C) & 1 & $85.27^{* *}$ \\
Evaluation times (ET) & 1 & $20.70^{* *}$ \\
C $\times$ ET & 1 & $5.18^{*}$ \\
\hline
\end{tabular}

${ }^{\mathrm{z}}$ Levels of probability: ${ }^{*}=0.05$ and $^{* *}=0.01$. 
$44 \%$. Blast severity showed a similar trend for the treatments as determined in a preliminary experiment (data not shown).

At least one of the factors, cultivars, and plant inoculation or evaluation times, as well as some of their interactions, were significant for $A, g_{s}, C_{\mathrm{i}}, E, V_{\mathrm{cmax}}, J_{\max }, J_{\max } / V_{\text {cmax }}$ ratio, and $R_{\mathrm{d}}$ (Table 2 ). Taken alone, plant inoculation was the most important factor (highest $F$ values) for explaining the variation in all of the traits evaluated. The interaction cultivar-plant inoculation-evaluation time was only significant for $C_{\mathrm{i}}$ and $R_{\mathrm{d}}$.

For BR 18 , the values of $A, g_{s}$, and $E$ decreased significantly at 48,72 , and 96 hai for inoculated plants compared with their noninoculated counterparts (Fig. 2). For BRS 229, significant decreases in $A$ were observed at 48, 72, and 96 hai, whereas for both $g_{s}$ and $E$, significant decreases occurred at 48 and 96 hai (Fig. 2). However, the disease-related reductions in these variables were proportionally greater at 96 hai for BR 18 than for BRS 229, with decreases of 99 and $78 \%$ for $A ; 53$ and $44 \%$ for $g_{s}$; and 43 and $38 \%$ for $E$, respectively. For $C_{\mathrm{i}}$, significant differences between inoculated and noninoculated plants were observed at 72 and 96 hai in BR 18 but only at 96 hai in BRS 229 (Fig. 2E and F), with the highest values found for inoculated plants. $C_{\mathrm{i}}$ was significantly increased by 32 and $14 \%$ at 96 hai for BR 18 and BRS 229, respectively, compared with noninoculated plants.

The correlations between $A$ and $C_{\mathrm{i}}$, as well as between blast severity and $A$, were negative and significant (Table 3 ). The parameter $g_{s}$ was positively correlated with $E$, and a positive and significant correlation was also observed between blast severity and $C_{\mathrm{i}}$.

Overall, $V_{\text {cmax }}$ and $J_{\max }$ decreased in both cultivars upon infection, although to a greater extent in BR 18 than in BR 229 (Fig. 3 ). These decreases were significant at 48,72 , and 96 hai in BR

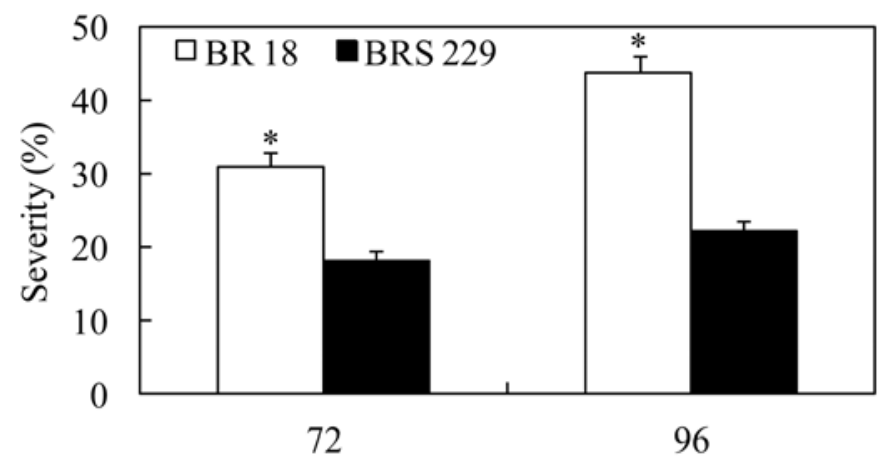

Hours after inoculation

Fig. 1. Blast severity on leaves of wheat plants from cultivars BR 18 and BRS 229. Means from cultivars BR 18 and BRS 299 followed by an asterisk (*), within each evaluation time, are significantly different $(P \leq 0.05)$ by $t$ test. Bars represent the standard error $(n=4)$ of the means. Two experiments were conducted with consistent results; results from one representative experiment are shown.
18 and at 48 and 96 hai $\left(V_{\mathrm{cmax}}\right)$, and only at 96 hai $\left(J_{\max }\right)$ in BRS 229 (Fig. 3). The $J_{\max } / V_{\text {cmax }}$ ratio was affected by plant inoculation at 48, 72, and 96 hai in BR 18 and only at 96 hai in BRS 229 (Fig. $3)$. Increases of 55 and $60 \%$ in the $J_{\max } / V_{\text {cmax }}$ ratio at 96 hai occurred for inoculated plants from cultivars BR 18 and BRS 229, respectively, compared with their noninoculated counterparts. The $R_{\mathrm{d}}$ increased significantly upon infection by $P$. oryzae (208\%), but only in BR 18 at 96 hai (Fig. 3).

A preliminary experiment to determine the gas exchange variables was performed and showed a similar trend for the treatments discussed above (data not shown).

\section{DISCUSSION}

To the best of our knowledge, this study is the first report demonstrating that $P$. oryzae infection reduces photosynthesis in wheat leaves. In a previous study, Debona et al. (13) showed that higher resistance, verified in BRS 229 relative to BR 18, was associated with a more efficient antioxidative system for the removal of the excess reactive oxygen species generated during the infectious process of $P$. oryzae. This resistance limited the cellular damage caused by $P$. oryzae. Debona et al. (13) found that BRS 229 was more resistant to leaf blast than BR 18. In the present study, the highest level of resistance for cultivar BRS 229 was related to less reduction in photosynthesis and the level of resistance was related to the reduction in photosynthesis caused by the $P$. oryzae infection. Additionally, the present work provides evidences of some mechanisms responsible for that reduction.

To explore the causes of $A$ impairments associated with $P$. oryzae infection, a detailed gas exchange analysis was carried out. It was first noted that, regardless of cultivar, proportionally larger decreases in $A$ than in $g_{s}$ were associated with increases in $C_{\mathrm{i}}$, which suggests that the lower influx of $\mathrm{CO}_{2}$ into leaves caused by stomatal closure was not a prominent factor in the reduction in $A$ in the diseased leaves. Additional support for this conclusion comes from the nonsignificant correlation between $A$ and $g_{s}$, the negative correlation between $A$ and $C_{\mathrm{i}}$, and the positive correlation between blast severity and $C_{\mathrm{i}}$. Similar results have been found in other pathosystems and these results have usually been interpreted as an indication of biochemical, rather than diffusive, limitations to photosynthesis $(1,12,34,35)$. However, this interpretation has proven to be inadequate in the current study because $\mathrm{CO}_{2}$ must also overcome other resistances, in addition to that offered by the stomata, when it diffuses from the intercellular air spaces into the carboxylation sites in the chloroplasts (mesophyll resistance) (38). Although such a mesophyllic effect cannot be ruled out, it is contended that the effect had only negligible importance in determining the photosynthetic capacity of diseased leaves of wheat plants under the experimental conditions of the present study, especially because $V_{\text {cmax }}$, which indicates the carboxylation capacity of Rubisco, was dramatically depressed at advanced stages of fungal infection. Therefore, in agreement with the working hypothesis of the present study, the decreases in $A$ may

TABLE 2. Analysis of variance of the effects of cultivars, plant inoculation, and evaluation times for the variables net carbon assimilate rate $(A)$, stomatal conductance to water vapor $\left(g_{s}\right)$, internal $\mathrm{CO}_{2}$ concentration $\left(C_{\mathrm{i}}\right)$, transpiration rate $(E)$, maximum rate of carboxylation $\left(V_{\text {cmax }}\right)$, maximum rate of electron transport used on ribulose-1,5-bisphosphate (RUBP) regeneration $\left(J_{\max }\right), J_{\max } / V_{\mathrm{cmax}}$ ratio, and respiration $\left(R_{\mathrm{d}}\right)$

\begin{tabular}{|c|c|c|c|c|c|c|c|c|c|}
\hline \multirow[b]{2}{*}{ Sources of variation } & \multirow[b]{2}{*}{ df } & \multicolumn{8}{|c|}{$F$ values $^{\mathrm{z}}$} \\
\hline & & $A$ & $g_{s}$ & $C_{\mathrm{i}}$ & $E$ & $V_{\text {cmax }}$ & $J_{\max }$ & $J_{\max } / V_{\text {cmax }}$ & $R_{\mathrm{d}}$ \\
\hline Cultivars (C) & 1 & $29.10^{* *}$ & $24.03^{* * *}$ & $15.86^{* *}$ & $18.84^{* *}$ & $22.77^{* *}$ & $0.97^{\mathrm{ns}}$ & $4.07^{\mathrm{ns}}$ & $0.14^{\mathrm{ns}}$ \\
\hline Plant inoculation (I) & 1 & $576.17^{* *}$ & $53.63^{* *}$ & $159.53^{* *}$ & $41.89^{* *}$ & $435.12^{* *}$ & $122.12^{* *}$ & $81.29^{* *}$ & $13.89^{* *}$ \\
\hline Evaluation times (ET) & 2 & $12.79^{* *}$ & $4.33^{*}$ & $8.51^{* *}$ & $2.14^{\mathrm{ns}}$ & $4.10^{*}$ & $6.71^{* *}$ & $5.55^{* *}$ & $1.26^{\mathrm{ns}}$ \\
\hline $\mathrm{C} \times \mathrm{I}$ & 1 & $103.67^{* *}$ & $10.70^{* *}$ & $21.60^{* *}$ & $5.34^{*}$ & $90.72^{* *}$ & $32.62^{* *}$ & $1.52^{\mathrm{ns}}$ & $0.71^{\mathrm{ns}}$ \\
\hline $\mathrm{C} \times \mathrm{ET}$ & 2 & $1.51^{\mathrm{ns}}$ & $0.85^{\mathrm{ns}}$ & $0.45^{\mathrm{ns}}$ & $0.03^{\mathrm{ns}}$ & $2.65^{\mathrm{ns}}$ & $2.21^{\mathrm{ns}}$ & $1.31^{\mathrm{ns}}$ & $0.66^{\mathrm{ns}}$ \\
\hline $\mathrm{I} \times \mathrm{ET}$ & 2 & $13.72^{* *}$ & $3.15^{\mathrm{ns}}$ & $46.21^{* *}$ & $0.91^{\mathrm{ns}}$ & $23.26^{* *}$ & $14.42^{* *}$ & $2.06^{\mathrm{ns}}$ & $0.53^{\mathrm{ns}}$ \\
\hline $\mathrm{C} \times \mathrm{I} \times \mathrm{ET}$ & 2 & $1.83^{\mathrm{ns}}$ & $0.56^{\mathrm{ns}}$ & $3.27^{*}$ & $0.14^{\mathrm{ns}}$ & $1.39^{\mathrm{ns}}$ & $1.37^{\mathrm{ns}}$ & $1.82^{\mathrm{ns}}$ & $3.40^{*}$ \\
\hline
\end{tabular}

${ }^{\mathrm{z}}$ Levels of probability: ${ }^{\mathrm{ns}}=$ not significant, ${ }^{*}=0.05$, and ${ }^{* *}=0.01$. 
be interpreted as arising from an impaired biochemical capacity for $\mathrm{CO}_{2}$ fixation.

In other plant species, such as rice, $P$. oryzae has been found to cause decreases in both Rubisco activity and RuBP regeneration capacity (indicated through $J_{\max }$ ) (41). Such a capability may be limited by the inability of the electron transport chain to provide reducing power and ATP supply, as well as by the loss or inactivation of enzymes involved in the Calvin cycle, other than Rubisco (2). Previous studies have shown that the inactivation of enzymes in the Calvin cycle, rather than limited reducing power or ATP supply, was associated with a reduction in $J_{\max }$ in tomatoes infected by Fusarium oxysporum f. sp. lycopersici (32) and potatoes infected by Potato virus $Y$ (43). In the present work, although a reduction in $J_{\max }$ due to infection by $P$. oryzae was found, the disease-induced increase in the $J_{\max } / V_{\text {cmax }}$ ratio suggests that the reduction in $A$ was not closely related to the decrease in the electron transport rate. Hence, it is posited that the reduced activity of Rubisco was the main factor associated with decreases
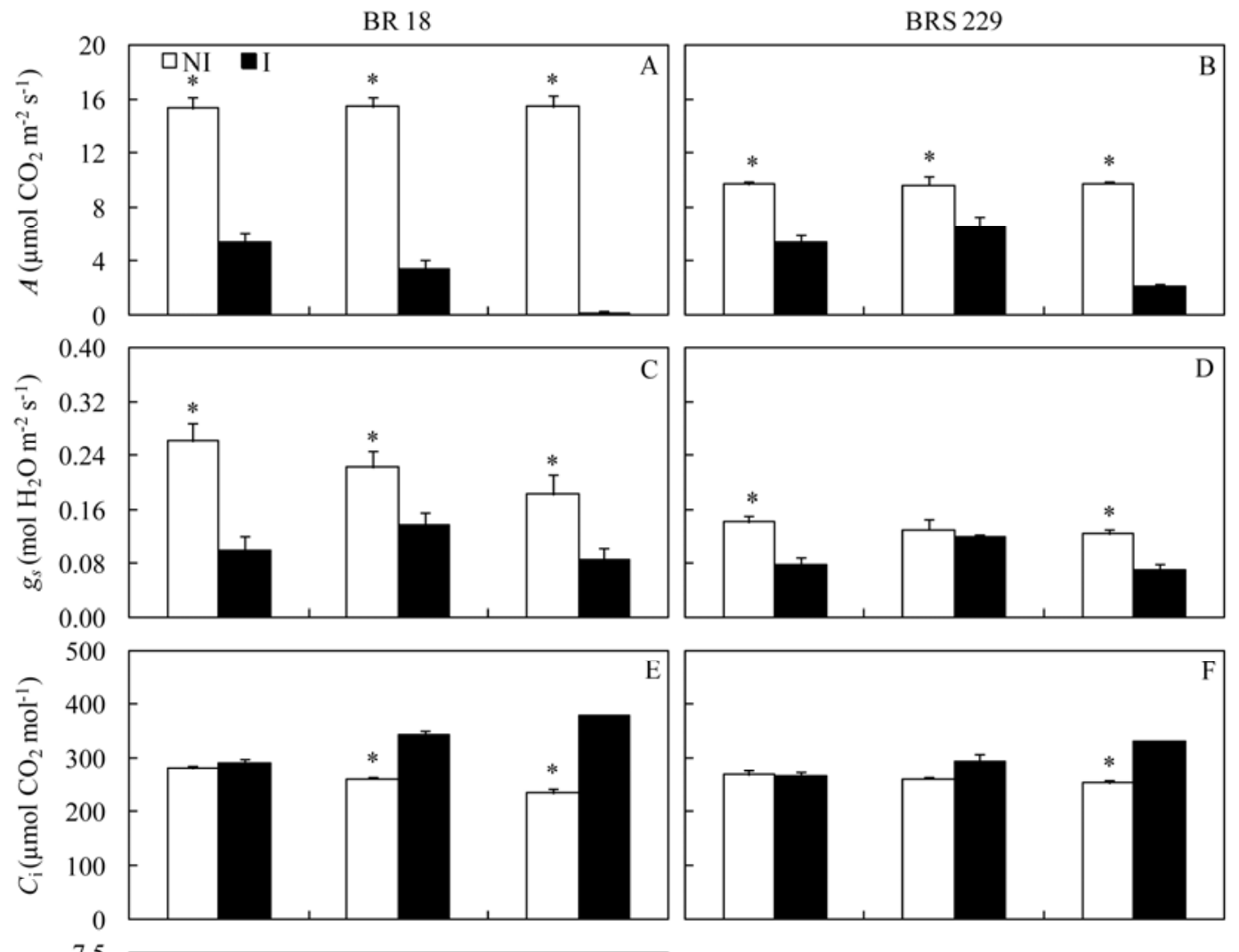

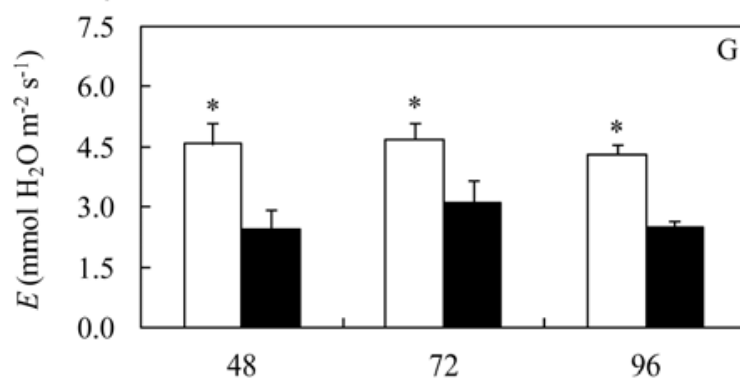

Hours after inoculation

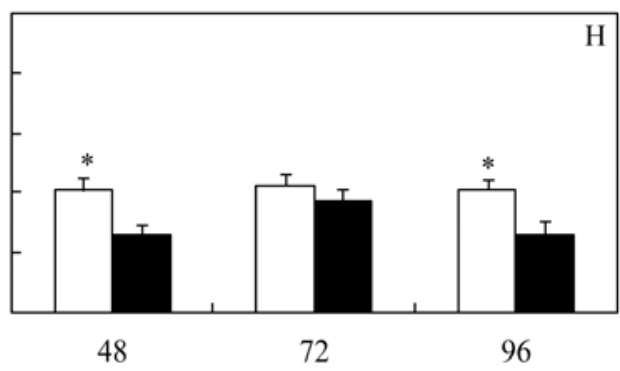

Hours after inoculation

Fig. 2. A and $\mathbf{B}$, Leaf gas exchange variables net carbon assimilation rate $(A), \mathbf{C}$ and $\mathbf{D}$, stomatal conductance to water vapor $\left(g_{s}\right)$, $\mathbf{E}$ and $\mathbf{F}$, internal $\mathbf{C O}_{2}$ concentration $\left(C_{\mathrm{i}}\right)$, and $\mathbf{G}$ and $\mathbf{H}$, transpiration rate $(E)$ determined on leaves of wheat plants from cultivars BR 18 (A, C, E, and G) and BRS $229(\mathrm{~B}, \mathrm{D}, \mathrm{F}$, and $\mathrm{H})$ noninoculated (NI) or inoculated (I) with Pyricularia oryzae. Means from NI and I treatments followed by an asterisk (*), within each evaluation time, are significantly different $(P \leq 0.05)$ by $t$ test. Bars represent the standard error $(n=4)$ of the means. Two experiments were conducted with consistent results; results from one representative experiment are shown.

TABLE 3. Correlation coefficients (above diagonal) and their respective $t$ values (below diagonal) among the net carbon assimilation rate (A), stomatal conductance to water vapor $\left(g_{s}\right)$, internal $\mathrm{CO}_{2}$ concentration $\left(C_{\mathrm{i}}\right)$, transpiration rate $(E)$, and blast severity in leaves of wheat plants from the cultivars BR 18 and BRS 229 inoculated with Pyricularia oryzae considering the evaluations made at 72 and $96 \mathrm{~h}$ after inoculation

\begin{tabular}{llllll}
\hline Variables $^{\mathrm{z}}$ & $A$ & $g_{s}$ & $C_{\mathrm{i}}$ & $E$ & Severity \\
\hline$A$ & - & 0.45 & -0.93 & 0.15 & -0.74 \\
$g_{s}$ & $1.86^{\mathrm{ns}}$ & - & -0.14 & 0.81 & 0.15 \\
$C_{\mathrm{i}}$ & $9.24^{*}$ & $0.54^{\mathrm{ns}}$ & - & - & 0.83 \\
$E$ & $0.55^{\mathrm{ns}}$ & $5.08^{*}$ & $0.56^{\mathrm{ns}}$ & $0.12^{\mathrm{ns}}$ & 0.03 \\
Severity & $4.07^{*}$ & $0.53^{\mathrm{ns}}$ & $5.53^{*}$ & - \\
\hline
\end{tabular}

${ }^{\mathrm{z}}$ Levels of probability: ${ }^{\mathrm{ns}}=$ not significant and ${ }^{*}=0.01$. 
in $A$ during the infection by $P$. oryzae. A similar result was obtained by Bassanezi et al. (4) for the bean- $U$. appendiculatus interaction.

The reduction in $A$ related to leaf diseases may theoretically be proportional to, proportionally greater than or proportionally smaller than, the corresponding reduction in green leaf area caused by a particular disease $(1,31,37)$. In the present study, despite the negative correlation between $A$ and blast severity, $A$ had already been reduced during the early stages of fungal infection (48 hai) when blast symptoms were not yet evident. Furthermore, the reduction in $A$ was proportionally greater than the blast severity. Collectively, these data suggest that asymptomatic tissues were also affected by $P$. oryzae. These results are in agreement with those observed for other pathosystems $(7,9,18,41)$. The decrease in $A$ in areas not yet colonized by $P$. oryzae may have been the result of toxins secreted by the fungus that diffused into surrounding areas of leaf tissue, causing tissue disintegration, and then compromising water and photo-assimilate translocation in leaf tissues distant from the infection site (7). Therefore, it is proposed that the extent of the diseased leaf area may not be a proper indicator of the potential impact of $P$. oryzae infection on $A$.

Some studies have demonstrated a concomitant reduction in $g_{s}$ and $E$ caused by foliar pathogens $(1,6,12,15,18,30)$. In contrast, increases in $E$ independent of the stomata have been observed after the sporulation of some fungi, such as those causing rust, due to the rupture of the leaf epidermis $(15,33)$. Considering that the last disease evaluation (96 hai) was assessed before $P$. oryzae sporulation, it is proposed that the decreases in $E$ were mainly governed by $g_{s}$, which was further corroborated by the positive and significant correlation between $E$ and $g_{s}$.

There were significant increases in $R_{\mathrm{d}}$ only for BR 18 at 96 hai, when disease symptoms were more prominent. In support of these results, Bassanezi et al. (6) observed that $R_{\mathrm{d}}$ for bean leaves increased only after the symptoms of rust, angular leaf spot, and anthracnose appeared. According to Lucas (29), $R_{\mathrm{d}}$ usually increases in leaves infected by hemibiotrophic and necrotrophic pathogens to meet the enhanced energetic demand caused by the accelerated metabolic activity of the host cells. Additionally, increases in $R_{\mathrm{d}}$ associated with fungal growth cannot be ruled out (3).

The results of the present study demonstrate that photosynthesis in wheat plants can be dramatically reduced during the process of infection by $P$. oryzae. The results from the modeling of $A / C_{\mathrm{i}}$ curves indicate that the decrease in wheat photosynthesis was mainly associated with a lower apparent Rubisco activity. All of the leaf gas exchange variables were less affected in the leaves
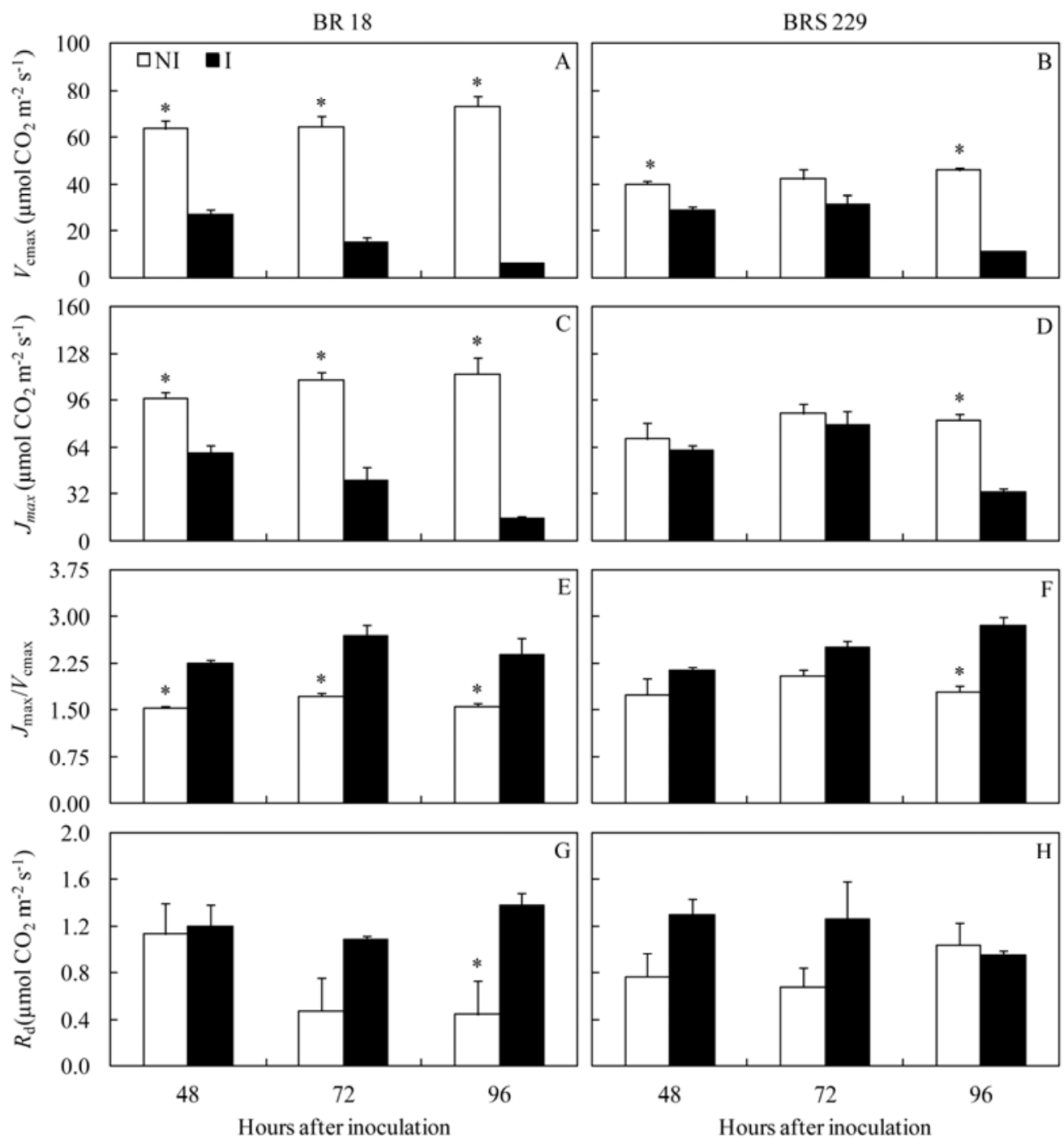

Fig. 3. A and B, Maximum rate of carboxylation $\left(V_{\mathrm{cmax}}\right), \mathbf{C}$ and $\mathbf{D}$, maximum rate of electron transport used on ribulose-1,5-bisphosphate (RuBP) regeneration $\left(J_{\max }\right), \mathbf{E}$ and $\mathbf{F}, J_{\max } / V_{\text {cmax }}$ ratio, and $\mathbf{G}$ and $\mathbf{H}$, respiration $\left(R_{\mathrm{d}}\right)$ determined in leaves of wheat plants from cultivars BR 18 (A, C, E, and G) and BRS 229 (B, D, F, and $\mathrm{H}$ ) noninoculated (NI) or inoculated (I) with Pyricularia oryzae. Means from NI and I treatments followed by an asterisk (*), within each evaluation time, are significantly different $(P \leq 0.05)$ by $t$ test. Bars represent the standard error $(n=4)$ of the means. Two experiments were conducted with consistent results; results from one representative experiment are shown. 
of the most resistant cultivar infected by $P$. oryzae. The results further suggest that asymptomatic tissues were also affected by $P$. oryzae. The effect of a particular disease on crop growth and yield may be predicted by the knowledge of physiological changes and the way that they are affected by the pathogen's life cycle $(8,10)$. Knowledge of the physiological alterations occurring in wheat leaves infected by $P$. oryzae may be leveraged into the development of efficient control strategies for wheat blast management. Breeding programs, for example, can select cultivars that are more efficient in carboxylation when inoculated with $P$. oryzae which may display relatively high yields even when grown in environments with favorable conditions for severe blast epidemics.

\section{ACKNOWLEDGMENTS}

F. A. Rodrigues and F. M. DaMatta thank the National Council for Scientific and Technological Development (CNPq) for their fellowship. D. Debona and J. A. Rios were supported by CNPq. We thank D. Lau and M. So e Silva (EMBRAPA-Centro Nacional de Pesquisa de Trigo) for providing the wheat seeds from the cultivars used in this study. This study was supported by grants from CAPES, CNPq, and FAPEMIG to F. A. Rodrigues.

\section{LITERATURE CITED}

1. Alves, A. A., Guimarães, L. M. S., Chaves, A. R. M., DaMatta, F. M., and Alfenas, A. C. 2011. Leaf gas exchange and chlorophyll $a$ fluorescence of Eucalyptus urophylla in response to Puccinia psidii infection. Acta Physiol. Plant 33:1831-1839.

2. Baker, N. R., Nogués, S., and Allen, D. J. 1997. Photosynthesis and photoinhibition. Pages 95-111 in: Plants and UV-B: Response to Environmental Change. P. J. Lumsden, ed. Cambridge University Press, Cambridge, UK.

3. Bancal, M.-O., Hansart, A., Sache, I., and Bancal, I. 2012. Modelling fungal sink competitiveness with grains for assimilates in wheat infected by a biotrophic pathogen. Ann. Bot. 110:113-123.

4. Bassanezi, R. B., Amorim, L., and Bergamin Filho, A. 2000. Análise das trocas gasosas em feijoeiro com ferrugem, mancha angular e antracnose. Fitopatol. Bras. 25:643-650.

5. Bassanezi, R. B., Amorim, L., Bergamin Filho, A., and Berger, R. D. 2001. Accounting for photosynthetic efficiency of bean leaves with rust, angular leaf spot and anthracnose to assess crop damage. Plant Pathol. 50:443-452.

6. Bassanezi, R. B., Amorim, L., Bergamin Filho, A., and Berger, R. D. 2002. Gas exchange and emission of chlorophyll fluorescence during the monocycle of rust, angular leaf spot and anthracnose on bean leaves as a function of their trophic characteristics. J. Phytopathol. 150:37-47.

7. Bastiaans, L. 1991. Ratio between virtual and visual lesion size as a measure to describe reduction in leaf photosynthesis of rice due to leaf blast. Phytopathology 81:611-615.

8. Bastiaans, L. 1993. Effects of leaf blast on photosynthesis of rice. 1. Leaf photosynthesis. Neth. J. Plant Pathol. 99:197-203.

9. Berger, S., Sinha, A. K., and Roitsch, T. 2007. Plant physiology meets phytopathology: Plant primary metabolism and plant-pathogen interactions. J. Exp. Bot. 58:4019-4026.

10. Boote, K. J., Jones, J. W., Smerage, G. H., Barfield, C. S., and Berger, R. D. 1980. Photosynthesis of peanut canopies as affected by leaf spot and artificial defoliation. Agron. J. 72:247-252.

11. Cruz, M. F. A., Prestes, A. M., Maciel, J. L. N., and Scheeren, P. L. 2010. Resistência parcial à brusone de genótipos de trigo comum e sintético nos estádios de planta jovem e de planta adulta. Trop. Plant Pathol. 35:24-31.

12. Dallagnol, L. J., Rodrigues, F. A., Martins, S. C. V., Cavatte, P. C., and DaMatta, F. M. 2011. Alterations on rice leaf physiology during infection by Bipolaris oryzae. Austral. Plant Pathol. 40:360-365.

13. Debona, D., Rodrigues, F. A., Rios, J. A., and Nascimento, K. J. T. 2012. Biochemical changes on the leaves of wheat plants infected by Pyricularia oryzae. Phytopathology 102:1121-1129.

14. Domiciano, G. P., Resende, R. S., Rodrigues, F. A., and DaMatta, F. M. 2009. Alteração na fotossíntese de plantas infectadas por patógenos. Rev. Ann. Patol. Plant. 17:305-339.

15. Duniway, J. M., and Durbin, R. D. 1971. Some effects of Uromyces phaseoli on the transpiration rate and stomatal response of bean leaves. Phytopathology 61:114-119.

16. Farquhar, G. D., Von Caemmerer, S., and Berry, J. A. 1980. A biochemical model of photosynthetic $\mathrm{CO}_{2}$ assimilation in leaves of $\mathrm{C}_{3}$ species. Planta 149:78-90.
17. Filha, M. S. X., Rodrigues, F. A., Domiciano, G. P., Oliveira, H. V., Silveira, P. R., and Moreira, W. R. 2011. Wheat resistance to leaf blast mediated by silicon. Austral. Plant Pathol. 40:28-38.

18. Godoy, C. V., Amorim, L., and Bergamin Filho, A. 2001. Alterações na fotossíntese e na transpiração de folhas de milho infetadas por Phaeosphaeria maydis. Fitopatol. Bras. 26:209-215.

19. Goulart, A. C. P., and Paiva, F. A. 1992. Incidência da brusone (Pyricularia grisea) em diferentes cultivares de trigo (Triticum aestivum) em condições de campo. Fitopatol. Bras. 17:321-325.

20. Goulart, A. C. P., and Paiva, F. A. 1993. Avaliação de fungicidas no controle da brusone (Pyricularia grisea) do trigo (Triticum aestivum). Fitopatol. Bras. 18:167-173.

21. Goulart, A. C. P., and Paiva, F. A. 2000. Perdas no rendimento de grãos de trigo causada por Pyricularia grisea, nos anos de 1991 e 1992, no Mato Grosso do Sul. Summa Phytopathol. 26:279-282.

22. Goulart, A. C. P., Sousa, P. G., and Urashima, A. S. 2007. Danos em trigo causados pela infecção de Pyricularia grisea. Summa Phytopathol. 33:358-363.

23. Habermann, G., Machado, E. C., Rodrigues, J. D., and Medina, C. L. 2003. $\mathrm{CO}_{2}$ assimilation, photosynthetic light response curves, and water relations of 'Pêra' sweet orange plants infected with Xylella fastidiosa. Braz. J. Plant Physiol. 15:79-87.

24. Harley, P. C., and Sharkey, T. D. 1991. An improved model of $\mathrm{C}_{3}$ photosynthesis at high $\mathrm{CO}_{2}$ : Reversed $\mathrm{O}_{2}$ sensitivity explained by lack of glycerate re-entry into the chloroplast. Photosynth. Res. 27:169-178.

25. Igarashi, S., Utiamada, C. M., Igarashi, L. C., Kazuma, A. H., and Lopes, R. S. 1986. Pyricularia sp. em trigo. Ocorrência de Pyricularia sp. no Estado do Paraná. Fitopatol. Bras. 11:351-352.

26. IRRI. 1996. Standard Evaluation System for Rice, 4th ed. International Rice Research Institute, Manila, Philippines.

27. Kohli, M. M., Mehta, Y. R., Guzman, E., De Viedma, L., and Cubilla, L. E. 2011. Pyricularia blast-A threat to wheat cultivation. Czech J. Genet. Plant Breed. 47:130-134.

28. Long, S. P., and Bernacchi, C. J. 2003. Gas exchange measurements, what can they tell us about the underlying limitations to photosynthesis? Procedures and sources of error. J. Exp. Bot. 54:2393-2401.

29. Lucas, J. A. 1998. Plant Pathology and Plant Pathogens. Blackwell Science, Oxford, UK.

30. McGrath, M. T., and Pennypacker, S. P. 1990. Alteration of physiological processes in wheat flag leaves caused by stem rust and leaf rust. Phytopathology 80:677-686.

31. Meyer, S., Saccardy-Adji, K., Rizza, F., and Genty, B. 2001. Inhibition of photosynthesis by Colletotrichum lindemuthianum in bean leaves determined by chlorophyll fluorescence imaging. Plant Cell Environ. 24:947-995

32. Nogués, S., Cotxarrera, L., Alegre, L., and Trillas, M. I. 2002. Limitations to photosynthesis in tomato leaves induced by Fusarium wilt. New Phytol. 154:461-470.

33. Owera, S. A. P., Farrar, J. F., and Whitbread, R. 1981. Growth and photosynthesis in barley infected with brown rust. Physiol. Mol. Plant Pathol. 18:79-90.

34. Pinkard, E. A., and Mohammed, C. L. 2006. Photosynthesis of Eucalyptus globulus with Mycosphaerella leaf disease. New Phytol. 170:119-127.

35. Resende, R. S., Rodrigues, F. A., Cavatte, P. C., Martins, S. C. V., Moreira, W. R., and DaMatta, F. M. 2012. Leaf gas exchange and oxidative stress in sorghum plants supplied with silicon and infected with Colletotrichum sublineolum. Phytopathology 102:892-898.

36. Sharkey, T. D. 1985. Photosynthesis in intact leaves of $\mathrm{C}_{3}$ plants: Physics, physiology and rate limitations. Bot. Rev. 51:53-105.

37. Shtienberg, D. 1992. Effects of foliar diseases on gas exchange processes: a comparative study. Phytopathology 82:760-765.

38. Tholen, D., and Zhu, X. G. 2011. The mechanistic basis of internal conductance: A theoretical analysis of mesophyll cell photosynthesis and $\mathrm{CO}_{2}$ diffusion. Plant Physiol. 156:90-105.

39. Urashima, A. S., and Kato, H. 1994. Varietal resistance and chemical control of wheat blast fungus. Summa Phytopathol. 20:107-112.

40. Urashima, A. S., and Kato, H. 1998. Pathogenic relationship between isolates of Pyricularia grisea of wheat and other hosts at different host developmental stages. Fitopatol. Bras. 23:30-35.

41. Yun, S.-C., Kim, P.-G., and Park, E. W. 2000. Alteration of gas exchange in rice leaves infected with Magnaporthe grisea. Plant Pathol. J. 16:279285.

42. Zadoks, J. C., Chang, T. T., and Konzak, C. F. 1974. A decimal code for the growth stages of cereals. Weed Res. 14:415-421.

43. Zhou, Y. H., Peng, Y. H., Lei, J. L., Zou, L. Y., Zheng, J. H., and Yu, J. Q. 2004. Effects of potato virus $Y^{\text {NTN }}$ infection on gas exchange and photosystem 2 function in leaves of Solanum tuberosum L. Photosynthetica 42:417-423. 